\title{
NTC sistem učenja i njegova primena u fizičkom vaspitanju predškolskog deteta
}

\author{
Luča Radmanić \\ Sandra Vujkov \\ Visoka strukovna škola za obrazovanje vaspitača i trenera, Subotica
}

\begin{abstract}
The aim of this study was to highlight the importance of early physical activity, because, apart from the health aspect, has consequences on the intellectual level. It was emphasized that the potential legacy formed in this way can not be overcome, and in the lack of early stimulation may not be reached. With movements and dance creativity and learning should be improved. Movement helps children develop not only the body but also their brains, learning ability and social skills. Exercise not only affects the physical development, but also cognitive, emotional and social development of the child. In the years of early childhood, it is important to create, with movement and play, solid connection between the brain, body and senses which significantly stimulate cognitive skills of the child.
\end{abstract}

Keywords: NTC learning system, physical education, kinesiology for additional stimulation of the synapses
Sažetak: Cilj ovog rada je bio da se istakne važnost rane fizičke aktivnosti, jer ona osim zdravstvenog aspekta, ima konsekvence i na intelektualnom planu. Naglašeno je da nasleđem formiran potencijal na ovaj način ne može biti prevaziđen, kao i da isti, odsustvom rane stimulacije ne može biti dostignut. Kretnjama i igrom treba poboljšavati kreativnost $\mathrm{i}$ učenje. Pokret pomaže deci razviti ne samo telo, već i njihov mozak, sposobnost učenja i društvene veštine. Vežbanje ne utiče samo na telesni razvoj, već i na kognitivni, emocionalni i socijalni razvoj deteta. U godinama ranog detinjstva važno je kretanjem i igrom stvoriti čvrste veze između mozga, tela $i$ čula, što znatno podstiču saznajne veštine deteta.

Ključne reči: NTC sistem učenja, fizičko vaspitanje, kineziološke aktivnosti za dodatnu stimulaciju razvoja sinapsi

Rad je primljen 18.05.2016.

Odobren 23.05.2016.

Kontakt podaci:

Luča Radmanić

Visoka škola strukovnih studija za obrazovanje vaspitača i trenera

Subotica, Banijska 67,

Tel: +38124547870

E-mail: lucharadmanic@gmail.com 


\section{Uvod}

Mnogobrojna istraživanja su potvrdila da rana stimulacija dece i učenje u predškolskom uzrastu imaju jako važnu ulogu na njihov kasniji razvoj. U prilog tome ide i analiza rezultata EPPE studije (The Effective Provision of Pre-School Education), rađene $\mathrm{u}$ Velikoj Britaniji i finansirane od Sekretarijata za decu, školu i porodicu, koja ističe da predškolsko obrazovanje ima presudan uticaj na postignuća $u$ kasnijim periodima života. Iz svega navedenog, proizilazi potreba i nužnost za programima koji bi u ranim uzrastima omogućili adekvatnu stimulaciju, učenje i razvoj. Program koji bez sumnje nudi mogućnost $\mathrm{za}$ to, posebno $\mathrm{u}$ predškolskom uzrastu, jeste i „NTC sistem učenja“. NTC sistem učenja (Nikola Tesla Centar - Odeljenje Mense za nadarenu decu), obelodanjen od strane dr Ranko Rajevića, koji je stvorio sistem učenja na teorijskim osnovama neurologije, neuropsihologije, a posebno pedagoških nauka (pedagogija porodice, didaktike i metodologije za predškolsko i osnovnoškolsko obrazovanje). Ovaj sistem pojašnjava kako učenje utiče na teorijsko znanje i daje uputstva o povezivanju teorije sa obrazovnom praksom. NTC predstavlja novi pristup učenju u kome dominiraju interakcija, aktivnosti razmišljanja deteta i njegov uspešan razvoj. Ovaj sistem učenja je razrađen u detalje i pokazao se kao vrlo dobar, primenljiv u porodici, predškolskim ustanovama i osnovnim školama (Rajević, 2010). Celokupan sistem je kompletno baziran na igri, te ga deca lako prihvataju i time razvijaju specifične sposobnosti učenja, memorisanja, misaonih procesa (funkcionlano znanje, rešavanje problema) u veoma ranom uzrastu. Osim toga, iskustva vaspitača, učitelja i nastavnika koji realizuju program „NTC - sistem učenja "pokazuju da program pokazuje jako dobre rezultate i u ranoj detekciji darovite dece, a isto tako je i stimulativan za njihov dalji razvoj. Do sada je sproveden niz istraživanja o efikasnosti NTC sistema učenja u odnosu na tradicionalni pristup, a osnovni nalazi odnose se na statističke značajnosti napredovanja nakon primene NTC sistema i pružaju indicije značajnog doprinosa NTC sistema učenja u razvoju divergentnog mišljenja i sistem razvijanja stvaralaštva, čija je teorijska osnova u: otkrivanju višeznačnosti datih činjenica i povećavanju vrednosti datih informacija; razvijanju strategija stvaralačkog učenja putem otkrića; razvijanju motivacionih komponenti stvaralaštva; sintezi empirijskog istraživanja i teorijskog uopštavanja; asocijativnoj osnovi otkrića; pronalaženju novog na osnovu nekompletnih činjenica i nedovoljno strukturisanog materijala; individualizaciji stvaralačkog učenja prema kognitivnom razvoju ispitanika.

Pojedina istraživanja jasno ukazuju da intelektualne sposobnosti zavise od broja sinapsi ( M. Diamond, Berceley. USA), koje se najviše formiraju do pete $(50 \%)$, do sedme $(75 \%)$ i do dvanaeste godine (95\%). Brzina stvaranja sinapsi i neuronskih puteva je neverovatno brza $u$ najranijem periodu života. Formiranje sinapsi i sazrevanje mozga se poklapaju sa dužinom REM faze spavanja, koja je najduža upravo u ranom detinjstvu. Rano stimulativno okruženje doprinosi razvoju velikog broja neuronskih puteva, što rezultira bogatom neuronskom mrežom, a to je presudno za kasnije dostizanje urođenih potencijala (Rajović, 2012).

\section{Mensa- NTC sistem učenja}

Mensa je organizacija koja okuplja ljude visokog koeficijenta inteligencije (IQ preko 148) i čiji je prevashodni zadatak istraživanje i primena inteligencije za korist šire društvene zajednice. Kako je već napomenuto generalni zahtevi MENSA Srbije stavljaju imperativ da učenje mora stimulisati kognitivne kapacitete dece, odnosno, pravovremeno stimulisati razvoj sinapsi, koje su direktno odgovorne za mentalno funkcionisanje (funkcionalno-logičke, asocijativne i konvergentno-divergentne) i treba ih primenjivati, vec u predškolskom uzrastu (Hilčenko \& Medić, 2015). U okviru Mense, odsek za darovite NTC (NIKOLA TESLA CENTAR), godinama istražuje problematiku poboljšanja intelektualnih sposobnosti, gde je i autor ovog programa, dr Ranko Rajović, dugogodišnji član četvoročlanog komiteta svetske Mense za darovitu decu. S obzirom na to da se nalazi na samom izvoru informacija i ima uvid u gotovo sve programe koji se sprovode širom sveta, okupio je tim eminentnih stručnjaka iz oblasti pedagogije, neurofiziologije, defektologije, psihologije i genetike, koji je uobličio efikasan i jednostavan program, sa mogućnošću praćenja i merenja postignutih rezultata. Prvenstvena namena NTC programa je identifikovanje i razvoj darovitih, mada su rezultati istraživanja pokazali da učenici sa lošijim uspehom pokazuju bolje rezultate primenom programa; da primena programa pomaže i razvoj poželjnih vrednosti kod učenika; da deca lakše uče $i$ brže memorišu podatke prilikom određenih fizičkih aktivnosti, kao i to da učenici kod kojih su identifikovane neke razvojne smetnje, pokazuju bolje rezultate u izvršavanju školskih obaveza. (Rajović $i$ sar., 2013). Važno je napomenuti da korist od programa imaju sva deca, jer aktivnosti na kojima se on zasniva doprinose 
razvoju bioloških potencijala svakog deteta, a osim toga na ovaj način može se preventivno uticati na otkrivanje i sprečavanje nastanka nekih razvojnih smetnji (disleksija, disgrafija, diskalkulija, itd).

\section{Problemi koji mogu nastati u razvoju}

Sazrevanje mozga je intenzivno u najranijem periodu detinjstva i više od $50 \%$ je završeno do pete godine. Ukoliko tada ne podstičemo dete, postoji mogućnost da neke od funkcija neće biti razvijene $\mathrm{u}$ punom obimu. Ako roditelji prepoznaju potrebe deteta i mogu da pomognu svojim podsticajem, sigurno će puno uraditi za svoje dete, jer će deo mozga zadužen za specifičnu veštinu biti bolje razvijen. Tako se stvaraju preduslovi da dete lakše koristi svoje kapacitete za razne tehnike u kasnijem periodu života.

Treba da ukažemo na važnost rane fizičke aktivnosti, jer ona osim zdravstvenog aspekta, ima konsekvence i na intelektualnom planu. Naglašavamo da nasleđem formiran potencijal na ovaj način ne može biti prevaziđen, kao i da isti odsustvom rane stimulacije ne može biti dostignut. Program stavlja $u$ centar odgovornost roditelja, jer je njegova uloga ključna i svakodnevna. Vaspitači mogu u ovom periodu da imaju naročito važnu ulogu i da pomognu roditeljima da pravilno usmeravaju dečije aktivnosti i time podstiču celokupni razvoj deteta. Mnogi roditelji i ne znaju da dozvoljavanjem pojedinih aktivnosti onemogućavaju pravilan razvoj svoje dece. Preterano gledanje televizije, igranje video igrica, nedostatak grafomotoričkih aktivnosti, fizička neaktivnost, oštećuju i smanjuju razvoj pojedinih bioloških potencijala. " U želji da zaštite dete, roditelji često sprečavaju neke izuzetno korisne aktivnosti npr: preskakanje faza razvoja pokreta - sedenje, puzanje, uspravljanje, stajanje, hodanje (preskakanje faze puzanja koja je važna za razvoj sake, a kasnije i pisanja); fiksiranje glave u 4. mesecu života držanje glave je uredu, ali ne i fiksiranje; nedostatak stimulansa boja (sobe beba su samo u plavoj ili ružičastoj boji; kupovina relaksatora bebe od 3 meseca života treba da se podižu sama sa rukama, a ne "ušuškavaju"; deca koja prohodaju se slobodno mogu " bacati" u vazduh (refleks hvatanja); skakanje (po krevetu) razvoj mišića i stvaranje sinapsi; zajednička igra (braća i sestre) - razvoj socijalizacije, više motoričkih aktivnosti; ravnoteža i balans (dete koje ne može da skače u nazad ne zna matematiku); rotacija (okretanje oko sebe u jednom pravcu otvorenih očiju) - stimulacija mozga; hodanje - ne razvijaju se najvažniji delovi mozga, ravna stopala; smanjenje energije kretanja - dete nema dinamičku akomodaciju oka (oko, šaka prsti), loša mu je grafomotorika, ne govori; žvakanje čvrste hrane (aktivira pokrete jezika, stimuliše koru velikog mozga za sticanje imunoglobulina, luči pljuvačku); trčanje (po neravnom terenu, preko prepreka) koje doprinosi razvoju mišića, bočnih pokreta stopala, akomodaciji oka, što je reakcija oka na količinu svetlosti i pokrete u prostoru. Rezultat toga je brzo zamaranje i lenjost očnih mišića, što izaziva ozbiljne smetnje u procesu čitanja, a samim tim proces usvajanja znanja i koncentracija je na jako niskom nivou." (Rajović, 2012).

\section{Realizacija programa i metodika rada}

NTC metod je koncipiran tako da daje niz smernica roditeljima i vaspitno-obrazovnim radnicima. Njegova odlika je da svako ko ga primenjuje u radu sa decom ima prostora za ličnu kreativnost, tj. aplikacije metode nisu konačne. Razvijajući dečiji potencijal, istovremeno "oslobađa" potencijal odraslih. Osim navedenog, prednost ove metode je u holističkom pristupu pojedncu, tj. u sve tri faze pokreću se prijatne emocije, pokriven je socijalni aspekt razvoja, a krajnji rezultat je kvalitetnije i dugotrajnije usvajanje gradiva, $\mathrm{tj}$. intelektualni aspekt.

Program se realizuje u više faza, u malim grupama (15-25), uz angažovanje stručnjaka i vaspitača sa sertifikatom „NTC SISTEM UČENJA“. Za svaki uzrast, uz primenu programa, rade se periodična testiranja, radi usmeravanja i praćenja razvoja dece. Neke od tih aktivnosti već postoje u radu sa decom predškolskog uzrasta, tako da Program daje samo manje modifikacije.

Program „NTC sistem učenja“ se sastoji iz tri celine: dodatna stimulacija razvoja sinapsi (igre ravnoteže, razvoj akomodacije i grafomotorike), stimulacija razvoja asocijativnog razmišljanja (apstrahovanje, vizualizacija, apstraktna klasifikacija i serijacija, asocijacije) i stimulacija razvoja funkcionalnog razmišljanja (zagonetne priče i zagonetna pitanja).

NTC metod je koncipiran tako da daje niz smernica roditeljima $i$ vaspitno-obrazovnim radnicima. Njegova odlika je da svako ko ga primenjuje u radu sa decom ima prostora za ličnu kreativnost, tj. aplikacije metode nisu konačne. Razvijajući dečiji potencijal, istovremeno "oslobađa" potencijal odraslih. Osim navedenog, prednost ove metode je u holističkom pristupu pojedncu, tj. u sve tri faze pokreću se prijatne 
emocije, pokriven je socijalni aspekt razvoja, a krajnji rezultat je kvalitetnije $\mathrm{i}$ dugotrajnije usvajanje gradiva, tj. intelektualni aspekt.

\section{Dodatna stimulacija razvoja sinapsi - kineziološke aktivnosti}

Motoričke sposobnosti predstavljaju one sposobnosti deteta koje učestvuju u rešavanju motoričkih zadataka i uslovljavaju uspešno kretanje (tzv. krupna motorika). One se ispoljavaju kako u jednostavnim, tako $\mathrm{i} u$ složenim pokretima (sposobnost izvođenja pokreta ruku, nogu ili tela sa određenom kontrolom). Sa druge strane, fina motorika (grafomotorika), je sposobnost da se prave precizni pokreti rukom uz zadržavanje dobre koordinacije između prstiju i oka.

Osnovni razlog svakodnevnog vežbanja, tj. sprovođenja motoričkih sposobnosti, jeste stimulacija razvoja neuronske mreže. U ovom programu se pre svega misli na vežbe koje se retko sprovode: rotacije, vežbe ravnoteže i vežbe za akomodaciju oka (R, Rajović, 2012).

$\mathrm{Na}$ fizičku aktivnost možemo gledati kao na potrebu, motiv čoveka, ali $\mathrm{i}$ na vrednost $\mathrm{u}$ psihološkom smislu, koja formira karakterističan stil života, posebno kod profesionalnih sportista. Može imati status i preventive, kao i upotrebe u terapijske svrhe. Ovaj rad je usmeren na značaj preventivne uloge fizičke aktivnosti, ali ne $u$ onom široko poznatom kontekstu, već na njenom doprinosu intelektualnom razvoju.

\section{Motoričke vežbe / aktivnosti}

Osnovni razlog svakodnevnog vežbanja, tj. sprovođenja motoričkih aktivnosti, jeste stimulacija razvoja neuronske mreže. Kao što je već navedeno, pre svega se misli na vežbe koje se retko sprovode: vežbe ravnoteže, rotacije i vežbe za akomodaciju oka.

Vežbe za akomodaciju oka - reakcija oka na količinu svetlosti i pokrete $\mathrm{u}$ prostoru, razvoj akomodacije - stimulacija razvoja očnih mišića. Gledanjem televizije, video igrica, kompjutera sve više se zapostavlja razvoj ove važne funkcije oka, što može da rezultira smanjenjem broja sinapsi u pojedinim regijama mozga. Akomodacija se razvija skoro u potpunosti do pete (sedme) godine brzim pokretima oka, praćenjem predmeta, trčanjem, preskakanjem prepreka. Lopta je idealno sredstvo za ove vežbe, jer prateći loptu oko stalno akomodira (igre kao što su: između dve vatre, dobacivanje lopte, ubacivanje u koš, kotrljanje lopte, itd). Vežbe trčanja, preskakanja, provlačenja, takođe, pomažu razvoj akomodacije oka.

Vežbe rotacije - Jedan od najkomplikovanijih pokreta u prostoru je rotacija oko svoje ose (strukture koje učestvuju u njemu su: vestibularni aparat - organ za održavanje ravnoteže i za informaciju o položaju tela u prostoru, strukture moždanog stabla, jedra velikog i malog mozga, III; IV i V kranijalni nervi - koji idu od motornih jezgara u moždanom stablu i sprovode impulse ka perifernim poprečno-prugastim mišićima). Ovakav komplikovani fiziološki proces mora da bude razvijen u ranim godinama života, kada se izgrađuju neuronski putevi. Postoji čitav niz vežbi iz ove grupe, a većina njih zahteva da se dete vrti raširenih ruku 10-15 sekundi oko svoje ose i posle toga održi ravnotežu. Nakon kratke pauze ciklus se ponavlja. Tu su i igre: "ćorave bake", okretanje oko obruča (grupa 3-4 deteta), trčanje po cik-cak linijama terena, okretanje u skoku, i sl.

Vežbe za ravnotežu - Isto kao i vežbe rotacije, vežbe za ravnotežu razvijaju veliki broj sinapsi. Ovde se ubrajaju razne vrste prevrtanja i skakanja, zatim hodanja po gredi, pravim i krivim linijama sa knjigom ili vrećicama na glavi, preskakanje niske grede, kretanje poskocima na jednoj nozi, vežbe sa lastišom i vijačom koje uključuju preskakanje, poskoke, itd.

Vežbe za finu motoriku - Fina motorika je sposobnost da se prave precizni sitni pokreti rukom uz zadržavanje dobre koordinacije između prstiju i oka. Fina motorika se razvija sa uzrastom: od početnih nespretnih pokušaja deteta da samostalno koristi kašiku, pokreti ruke, tj. Sake, vremenom postaju precizniji, sve do momenta kada dete može da uzme olovku i da je kontroliše. Za uspešno ovladavanje procesom pisanja koje dete čeka u školi, potrebno je najpre razviti finu motoriku mišića šake i prstiju. Vežbe za finu motoriku moraju da budu svakodnevne, ne samo zbog pripreme za pisanje, već zbog toga što prsti zauzimaju veliki deo kore velikog mozga i time značajno mogu da utiču na broj sinapsi $i$ povećanje intelektualnih sposobnosti. Fina motorika je od suštinskog značaja za pisanje, što predstavlja razlog da se ta veština razvija i kod kuće, mnogo pre polaska u školu. U vežbe za razvoj fine motorike ( grafomotorike) ubrajaju se i igre sa: lego kockama, bockalice, plastelinom, glinom, testom, klikerima, seckanje makazicama mnoge druge. 


\section{Zaključak}

Primenom programa "Mensa NTC sistem učenja" podiže se nivo intelektualnih sposobnosti sve dece koja učestvuju u programu, sprečava se poremećaj koncentracije i pažnje, kasnije u školskom periodu (disleksija), razvija se koordinacija pokreta i motorike, razvija se brzina razmišljanja i zaključivanja (funkcionalno znanje), sva deca imaju korist od programa, a posebno je koristan za detekciju darovite dece i podsticanje razvoja darovitosti. Bitno je da se u predškolskom uzrastu u svakodnevni rad unesu elementi koji stimulišu mentalni razvoj dece, ali i specifične vežbe koje razvijaju koordinaciju pokreta i motoriku i na taj način sprečavaju poremećaj koncentracije i pažnje u kasnijem periodu života. Program savetuje da se primenjuju proverene i korisne aktivnosti i igre, kao što su: klikeri, lastiš, školice, mape uma, šah, itd. 


\section{Literatura}

1. Gojkov, G., Rajović, R., Stojanović, A., (2015). NTC learning system i divergentna produkcija. Istraživanja u pedagogiji, 5 (1), 105-126.

2. Rajović, R. (2009). NTC sistem učenja, iq deteta- briga roditelja (I deo predškolski uzrast, Abeceda d.o.o., Novi Sad)

3. Rajović, R. (2010). NTC sistem učenja - metodički priručnik za vaspitače. Vršac: Visoka škola strukovnih studija za obrazovanje vaspitača "Mihailo Palov"

4. Rajović, R. (2012). NTC sistem učenja, metodički priručnik za primenu programa,( II deo: uzrast 4 do 8 godina- kako uspešno razvijati iq deteta kroz igru, Smart production d.o.o. Novi Sad)

5. Rajović, R., Srbije,M., Sad,N., Cikoš, M.D., Mladost, P.U., \& Palanka, B.(2013). Razvoj sposobnosti dece predškolskog uzrasta i detekcija darovite dece (Primena programa NTC sistem učenja), Zbornik radova, 9 Međunarodna konferencija, Alfa univerzitet Fakultet za menadžment u sportu Ministarstvo prosvete, nauke i tehnološkog razvoja Republike Srbije Olimpijski komitet Srbije, Fakultet za menadžment u sportu, Beograd 